\title{
EFICIÊNCIA DO HERBICIDA SULFENTRAZONE NO CONTROLE, EM PRÉ-EMERGÊNCIA, DE PLANTAS DANINHAS EM SOJA
}

\author{
Fernando T. Carvalho ${ }^{1}$, W. Galbiatti Jr. ${ }^{2}$ e M. A. Cavazzana ${ }^{1}$
}

${ }^{1}$ FEIS/UNESP. Av. Brasil, 56. Caixa Postal 31. Ilha Solteira, SP 15385-000. E.mail: ftadeu@bio.feis.unesp.br

2 Prefeitura Municipal. Estrela d'Oeste, SP

\section{RESUMO}

O experimento foi desenvolvido na Fazenda de Ensino e Pesquisa da Universidade Estadual Paulista em Selvíria-MS, enquadrada em região de Cerrado. O objetivo do trabalho foi o de avaliar o herbicida sulfentrazone quanto à seletividade às plantas de soja, cultivar IAC-15 e sua eficiência no controle, em pré-emergência, de plantas daninhas. Os tratamentos foram constituídos pelos herbicidas sulfentrazone, imazaquim + clethodim, fomesafen + clethodim e testemunhas capinada e sem capina. Concluiu-se que o herbicida sulfentrazone, nas doses de 500, 550 e $650 \mathrm{~g} /$ ha, provoca baixos sintomas de toxicidade à cultura da soja e uma ligeira diminuição, não significativa, na altura das plantas de soja. O sulfentrazone foi seletivo às plantas de soja e eficiente no controle de Acanthospermum hispidum, Bidens pilosa, Commelina benghalensis e Cenchrus echinatus.

Palavras-chave: Glycine max, Cerrado, Acanthospermum hispidum, Bidens pilosa, Commelina benghalensis, Cenchrus echinotus.

\section{ABSTRACT \\ Efficacy of the herbicide sulfentrazone in preemergence control of weeds in soybean}

The experiment was conducted at the Teaching and Research Farm of the State University of São Paulo, in SelviriaMS, a region of Cerrados vegetation. The objective of the study was to evaluate the selectivity and efficacy of preemergence application of sulflentrazone in soybean. Treatments included sulfentrazone at 500,550 and $600 \mathrm{~g} / \mathrm{ha}$, sequential postemergence application of imazaquim and clethodim at $140+72 \mathrm{~g} / \mathrm{ha}$ and tank mixed fomesafen + clethodim at $250+72 \mathrm{~g} / \mathrm{ha}$. A weedy and a weeded control were also included. Sulfentrazone at all rates caused very low toxicity symptoms in soybean, IAC-15 cultivar, and gave good control of Acanthospermum hispidium, Bidens pilosa, Commelina benghalensis and Cenchrus echinatus.

Key words: Glycine max, Acanthospermum hispidium, Bidens pilosa, Commelina benghalensis Cenchrus echinatus, Savanna.

\section{INTRODUÇÃO}

A cultura da soja (Glycine max) está sujeita a vários tipos de danos e sua produtividade pode variar em função do ataque de pragas, ocorrência de doenças e convivência com plantas daninhas, sob determinadas condições edafoclimáticas.

As plantas daninhas são as maiores responsáveis pela queda de produção da soja, em comparação com ataques de pragas e de patógenos. As médias das perdas mundiais de produção de grãos de soja, por ano, devido à ocorrência de plantas daninhas são de $13 \%$, enquanto que devido ao ataque de pragas e doenças são de 5 e $11 \%$, respectivamente (Associação Nacional de Defensivos Agrícolas - ANDEF, 1987). Entretanto, no clima tropical do Brasil, tem sido observado perdas bem maiores. Blanco et al. (1973 e 1978) observaram prejuízos na produtividade da soja que variaram de 42 a $95 \%$, dependendo das espécies daninhas infestantes. Barros 
et al. (1992) observaram perdas médias de produtividade de 69,4\% para o cultivar Emgopa 304.

Existem diferentes métodos para o controle das plantas daninhas. Na cultura da soja, devido às extensas áreas cultivadas, o controle químico é o que tem sido mais utilizado, em função da eficácia do controle e do alto rendimento operacional que se consegue nas aplicações. Atualmente, levando-se em consideração a média de dez a doze milhões de hectares cultivados com a soja no Brasil, o uso de herbicidas é imprescindível.

Os herbicidas utilizados em pré-emergência são muito úteis no controle de plantas daninhas nas culturas, devido à vantagem de possibilitar um bom planejamento da lavoura, permitindo que não haja acúmulo de áreas para serem aplicadas no curto período em que os de pós-emergência são eficientes. Desta forma, a busca por herbicidas de pré-emergência, seletivos para a soja e de largo espectro de controle, torna-se totalmente justificável.

O objetivo do presente trabalho foi avaliar o herbicida sulfentrazone quanto à seletividade às plantas de soja e sua eficiência no controle em pré-emergência das plantas daninhas.

\section{MATERIAL E MÉTODOS}

O experimento foi conduzido no período de novembro/96 a março/97, na Fazenda de Ensino e Pesquisa da Universidade Estadual Paulista, situada a $20^{\circ} 22^{\prime}$ de latitude sul, $51^{\circ} 22^{\prime}$ de longitude oeste, 335 metros de altitude, no município de Selvíria-MS, enquadrada em região de cerrado. O solo da área experimental é classificado como Latossolo Vermelho-Escuro, textura média.

Antes da instalação do experimento o solo foi preparado de maneira convencional, o que eliminou as plantas daninhas que já haviam germinado. A variedade de soja utilizada foi a 'IAC-15', semeada mecanicamente no dia 18/ $11 / 96$, no espaçamento de $50 \mathrm{~cm}$ entre-linhas.

Os herbicidas residuais selecionados para o teste experimental foram aplicados em pré-emergência da cultura e das plantas daninhas, e os de pós-emergência, aos 25 dias após a semeadura, quando a cultura encontrava-se com três trifólios e as plantas daninhas dicotiledôneas com até 3 pares de folhas.

Os tratos culturais realizados na área experimental foram os normais exigidos pela cultura, no que diz respeito às adubações e ao controle de pragas e doenças.

Os tratamentos utilizados no experimento estão apresentados na Tabela 1 e as características dos herbicidas na Tabela 2.
O delineamento experimental adotado foi o de blocos ao acaso, com sete tratamentos e quatro repetições. Cada parcela constou de 8 linhas da cultura (espaçadas de $0,5 \mathrm{~m}$ ), com $6 \mathrm{~m}$ de comprimento, totalizando $24 \mathrm{~m}^{2}$. A área total do experimento (28 parcelas) foi de $672 \mathrm{~m}^{2}$.

As aplicações dos herbicidas foram realizadas com um pulverizador costal com pressão constante $\left(\mathrm{CO}_{2}\right)$ de 3,16 $\mathrm{kg} / \mathrm{cm}^{2}$, provido de tanque com capacidade de dois litros (garrafas descartáveis), e com barra equipada com quatro bicos do tipo leque, marca Teejet 110.03 , espaçados de $0,5 \mathrm{~m}$. O volume de calda aplicado foi de 300 litros por hectare.

As aplicações foram realizadas em pré e pós-emergência da cultura e das plantas daninhas, conforme o tratamento (Tabela 1). Na época das aplicações o solo encontrava-se adequadamente úmido para aplicação de herbicidas. No tratamento 2 (testemunha no limpo) o controle das plantas daninhas foi feito manualmente, de quinze em quinze dias, até o fechamento da cultura.

As avaliações de eficiência dos produtos foram realizadas através de uma escala de observações visuais baseadas em percentual de notas, onde zero corresponde a nenhum controle e cem controle total das plantas daninhas, comparando-se os tratamentos com a testemunha no mato.

As avaliações de seletividade também foram realizadas visualmente, comparando-se os tratamentos com a testemunha no limpo e estimando-se a percentagem de fitotoxicidade ( 0 a 100) proporcionada pelos herbicidas.

As avaliações de eficiência e seletividade foram realizadas aos 15, 25, 35 e 50 dias após a semeadura (DAS). As avaliações de fitotoxicidade foram realizadas até o desaparecimento dos sintomas na cultura e as avaliações de controle de plantas daninhas até o fechamento da cultura.

Foram avaliadas também as características de crescimento e produtividade da cultura, para auxiliar na interpretação dos resultados. As avaliações de crescimento foram realizadas medindo-se a altura de 5 plantas, em linha, da área central de cada parcela, aos 32 e 110 dias após a semeadura. A avaliação de produtividade foi realizada aos 122 DAS colhendo-se e os grãos da área útil, ou seja, os $2 \mathrm{~m}^{2}$ centrais de cada parcela.

\section{RESULTADOS E DISCUSSÃO}

As espécies daninhas de ocorrência natural, que se apresentaram com maior frequência nas testemunhas sem capinas foram: Acanthospermum hispidum (carrapicho-de-carneiro), Bidens pilosa (picão-preto), Commelina benghalensis (trapoeraba) e Cenchrus echinatus (capim-carrapicho). Outras espécies que ocorreram com nível de infestação menor do que $10 \%$ não foram consideradas (Tabela 3). 
Tabela 1. Tratamentos utilizados no teste experimental do herbicida sulfentrazone em soja. Selvíria - MS, 1997.

\begin{tabular}{lccc}
\hline & Época de & \multicolumn{2}{c}{ Dose dos Herbicidas } \\
\cline { 3 - 4 } Tratamento & $\begin{array}{c}\text { Aplicação } \\
\text { Principio Ativo } \\
\text { (g/ha) }\end{array}$ & $\begin{array}{c}\text { Produto } \\
\text { comercial }(\text { /ha) }\end{array}$ \\
\hline Testemunha no mato & - & - & - \\
Testemunha no limpo & - & - & - \\
Sulfentrazone (Boral 500 SC) & PRÉ & 500 & 1,01 \\
Sulfentrazone (Boral 500 SC) & PRÉ & 550 & 1,11 \\
Sulfentrazone (Boral 500 SC) & PRÉ & 600 & 1,21 \\
Imazaquin + clethodim (Scepter 70 DG + Select 240 CE) & PRÉ + PÓS & $140+72$ & $0,2 \mathrm{~kg}+0,31$ \\
Fomesafen + clethodin (Flex + Select 240 CE) & PÓS + PÓS & $250+72$ & $1,01+0,31$ \\
\hline
\end{tabular}

i.a. $=$ ingrediente ativo

Tabela 2. Características dos herbicidas utilizados no experimento. Selvíria-MS, 1997.

\begin{tabular}{lllllc}
\hline \multicolumn{1}{c}{$\begin{array}{c}\text { Nome } \\
\text { comercial }\end{array}$} & \multicolumn{1}{c}{$\begin{array}{c}\text { Nome } \\
\text { técnico }\end{array}$} & \multicolumn{1}{c}{ Formulação } & $\begin{array}{c}\text { Concentração do } \\
\text { ingrediente ativo } \\
\text { (g/litro) }\end{array}$ & Grupo químico & Classe toxicológica \\
\hline Boral 500 SC & sulfentrazone & suspensão concentrada & 500 & aril triazolinonas & IV \\
Scepter DG & imazaquin & concentrado solúvel & 150 & imidazolinonas & IV \\
Select 240 CE & clethodim & concentrado emulsionável & 240 & ciclohexenonas & III \\
Flex & fomesafen & solução aquosa concentrada & 250 & difenil-éter & I \\
\hline
\end{tabular}

Tabela 3. Percentagem média de infestação das plantas daninhas nas testemunhas sem capinas. Selvíria-MS, 1997.

\begin{tabular}{lcccc}
\hline \multirow{2}{*}{ Espécie daninha } & \multicolumn{4}{c}{$\begin{array}{c}\text { \% Média de infestação } \\
\text { Dias após a semeadura }\end{array}$} \\
\cline { 2 - 5 } & $\mathbf{1 5}$ & $\mathbf{2 5}$ & $\mathbf{3 5}$ & $\mathbf{5 0}$ \\
\hline Acanthospermum hispidum & 10 & 12 & 14 & 17 \\
Bidens pilosa & 0 & 0 & 9 & 12 \\
Commelina benghalensis & 5 & 10 & 11 & 13 \\
Cenchrus echinatus & 5 & 10 & 12 & 13 \\
\hline
\end{tabular}

As dicotiledôneas Acanthospermum hispidum e Bidens pilosa são citadas entre as que ocorrem com maior frequência na cultura da soja nos Estados do Centro-Oeste e Sul do país, segundo levantamento realizado por Kissmann (1976). As espécies daninhas Commelina benghalensis e Cenchrus echinatus são citadas entre as principais monocotiledôneas que ocorrem na cultura da soja, na região Sudeste, segundo Gelmini \& Diehl (1983).

Os dados de percentagem de controle (média das quatro repetições) de plantas daninhas do experimento, estão contidos nas Tabelas 4 e 5 .

As dicotiledôneas anuais Acanthospermum hispidum e Bidens pilosa, a monocotiledônea perene Commelina benghalensis e a anual Cenchrus echinatus, ocorreram no experimento com picos de desenvolvimento aos 50 DAS, alcançando infestações médias, na testemunha sem capina, de $17 \%, 12 \%, 13 \%$ e $13 \%$, respectivamente. As Tabelas 3, 4 e 5 apresentam as atuações dos herbicidas no controle dessas plantas daninhas.

Observa-se que todos os tratamentos com herbicidas foram eficientes no controle das plantas daninhas, proporcionando médias de controle acima de $90 \%$ até os 50 DAS. Após este período ocorreu o fechamento da cultura e o sombreamento impediu a reinfestação das ervas.

O herbicida sulfentrazone proporcionou médias de controle das plantas daninhas acima dos tratamentos padrões 
Tabela 4. Percentagem média de controle no teste experimental do herbicida sulfentrazone em soja. Selvíria-MS, 1997.

\begin{tabular}{|c|c|c|c|c|c|c|}
\hline \multirow{3}{*}{ Tratamento } & \multicolumn{6}{|c|}{ Dias após a semeadura } \\
\hline & 15 & 25 & 35 & 50 & 35 & 50 \\
\hline & \multicolumn{4}{|c|}{ Acanthospermum hispidum } & \multicolumn{2}{|c|}{ Bidens pilosa } \\
\hline Testemunha no mato & - & - & - & - & 9 & 12 \\
\hline Testemunha no limpo & 100 & 100 & 100 & 100 & 100 & 100 \\
\hline Boral $500 \mathrm{SC}(1,0$ l/ha $)$ & 100 & 100 & 100 & 100 & 100 & 100 \\
\hline Boral 500 SC $(1,1$ 1/ha $)$ & 100 & 100 & 100 & 100 & 100 & 100 \\
\hline Boral $500 \mathrm{SC}(1,2$ 1/ha $)$ & 100 & 100 & 100 & 100 & 100 & 100 \\
\hline Scepter $70 \mathrm{DG}(0,2 \mathrm{~kg} / \mathrm{ha})+$ Select $240 \mathrm{CE}(0,3 \mathrm{l} / \mathrm{ha})$ & 100 & 100 & 97 & 96 & 100 & 100 \\
\hline Flex $(1,0$ l/ha $)+$ Select $240 \mathrm{CE}(0,3 \mathrm{l} / \mathrm{ha})$ & - & - & 98 & 100 & 100 & 100 \\
\hline
\end{tabular}

Tabela 5. Percentagem média de controle no teste experimental do herbicida sulfentrazone em soja. Selvíria-MS, 1997.

\begin{tabular}{|c|c|c|c|c|c|c|}
\hline \multirow{3}{*}{ Tratamento } & \multicolumn{6}{|c|}{ Dias Após a Semeadura } \\
\hline & 25 & 35 & 50 & 25 & 35 & 50 \\
\hline & \multicolumn{3}{|c|}{ Commelina benghalensis } & \multicolumn{3}{|c|}{ Cenchrus echinatus } \\
\hline Testemunha no mato & -- & -- & -- & -- & -- & -- \\
\hline Testemunha no limpo & 100 & 100 & 100 & 100 & 100 & 100 \\
\hline Boral $500 \mathrm{SC}(1,0 \mathrm{l} / \mathrm{ha})$ & 100 & 98 & 92 & 100 & 97 & 96 \\
\hline Boral 500 SC $(1,11 /$ ha $)$ & 100 & 100 & 93 & 100 & 100 & 97 \\
\hline Boral $500 \mathrm{SC}(1,2$ 1/ha $)$ & 100 & 100 & 94 & 100 & 100 & 98 \\
\hline Scepter 70 DG $(0,2 \mathrm{~kg} / \mathrm{ha})+$ Select $240 \mathrm{CE}(0,31 / \mathrm{ha})$ & 79 & 80 & 90 & 84 & 86 & 92 \\
\hline Flex $(1,0 \mathrm{l} / \mathrm{ha})+$ Select $240 \mathrm{CE}(0,3 \mathrm{l} / \mathrm{ha})$ & - & 100 & 90 & - & 98 & 94 \\
\hline
\end{tabular}

Tabela 6. Percentagem média de fitotoxicidade dos herbicidas no teste experimental do herbicida sulfentrazone. SelvíriaMS, 1997.

\begin{tabular}{|c|c|c|c|c|c|c|}
\hline \multirow{3}{*}{ TRATAMENTO } & \multicolumn{6}{|c|}{ Dias A pós a Semeadura } \\
\hline & 15 & 25 & 35 & 32 & 110 & 122 \\
\hline & \multicolumn{3}{|c|}{$\begin{array}{c}\text { Mé dia de fitotoxici dade } \\
(\%)\end{array}$} & \multicolumn{2}{|c|}{$\begin{array}{c}\text { Altura de plantas } \\
(\mathrm{cm})\end{array}$} & $\begin{array}{c}\text { Produção } \\
\text { (kg/ha) }\end{array}$ \\
\hline Testemunha no mato & - & - & - & 29,6 a & 95,8 a & $1626 \mathrm{~b}$ \\
\hline Testemunha no limpo & - & - & - & $28,6 \mathrm{a}$ & $92,2 \mathrm{a}$ & $2446 \mathrm{a}$ \\
\hline Boral $500 \mathrm{SC}(1,0 \mathrm{l} / \mathrm{ha})$ & 1 & 3 & 0 & $26,4 \mathrm{a}$ & 89,2 a & $2026 \mathrm{ab}$ \\
\hline Boral $500 \mathrm{SC}(1,1 \mathrm{l} / \mathrm{ha})$ & 3 & 4 & 3 & $26,4 \mathrm{a}$ & 86,5 a & $2396 \mathrm{a}$ \\
\hline Boral $500 \mathrm{SC}(1,21 / \mathrm{ha})$ & 4 & 6 & 3 & $26,4 \mathrm{a}$ & 85,9 a & $1996 \mathrm{ab}$ \\
\hline Scepter $70 \mathrm{DG}(0,2 \mathrm{~kg} / \mathrm{ha})+$ Select $240 \mathrm{CE}(0,3 \mathrm{l} / \mathrm{ha})$ & 0 & 0 & 0 & $27,2 \mathrm{a}$ & $91,1 \mathrm{a}$ & $2369 \mathrm{a}$ \\
\hline Flex $(1,0 \mathrm{l} / \mathrm{ha})+$ Select $240 \mathrm{CE}(0,3 \mathrm{l} / \mathrm{ha})$ & - & - & 8 & $29,0 \mathrm{a}$ & $90,8 \mathrm{a}$ & $2329 \mathrm{a}$ \\
\hline MÉDIA & & & & 27,45 & 90,23 & 2170 \\
\hline TESTE F & & & & $3,2238^{\mathrm{NS}}$ & $1,2095^{\mathrm{NS}}$ & $4,0815^{*}$ \\
\hline CV $(\%)$ & & & & 7,2 & 6,9 & 13,7 \\
\hline DMS $(5 \%)$ & & & & 4,6 & 14,4 & 692,7 \\
\hline
\end{tabular}

(*) Médias seguidas de letras iguais nas colunas não diferem entre si ao nível de significância de $5 \%$ de probabilidade, pelo teste de Tukey. 
testados. Para as dicotiledôneas, Acanthospermum hispidum e Bidens pilosa, o herbicida proporcionou controle médio de $100 \%$, até os 50 DAS. Para as monocotiledôneas Commelina benghalensis e Cenchrus echinatus, o sulfentrazone proporcionou controle médio acima de $92 \%$ e $96 \%$, respectivamente, até os $50 \mathrm{DAS}$. Os resultados obtidos estão de acordo com as recomendações de Rodrigues \& Almeida (1995) no que diz respeito à eficiência de sulfentrazone, para essas quatro ervas.

Observa-se que todos os tratamentos proporcionaram baixos sintomas de toxicidade às plantas de soja (Tabela 6). O herbicida sulfentrazone provocou sintomas de fitotoxicidade menores que $6 \%$.

Os efeitos dos herbicidas sobre a cultura podem ser observados, também, pelos dados de crescimento das plantas (Tabela 6). Observa-se que os tratamentos com sulfentrazone provocaram uma ligeira diminuição na altura das plantas, entretanto, não houve diferença significativa entre os tratamentos, nos dados deste parâmetro.

\section{CONCLUSÕES}

1. Os herbicidas Boral $(1,0,1,1$ e 1,2 1/ha), Scepter + Select $(0,2+0,3 \mathrm{l} / \mathrm{ha})$ e Flex + Select $(1,0+0,3 \mathrm{l} / \mathrm{ha})$ provocam, inicialmente (aos 15 e 25 DAS), baixos sintomas de toxicidade à cultura da soja, que diminuem aos 35 DAS e desaparecem completamente aos 50 DAS.

2. O herbicida Boral provoca uma ligeira diminuição, não significativa, na altura das plantas de soja, cultivar IAC-15.

3. O herbicida Boral é eficiente no controle de Acanthospermum hispidum, Bidens pilosa, Commelina benghalensis e Cenchrus echinatus, e pode ser recomendado para o controle seletivo de plantas daninhas na cultura da soja, nas doses de 1,0 e 1,1 1/ha.

\section{LITERATURA CITADA}

ASSOCIAÇÃO NACIONAL DE DEFENSIVOS AGRÍCOLAS - ANDEF. Defesa vegetal. São Paulo-SP: ANDEF, 1987. $19 \mathrm{p}$.

BARROS, A.C.; MATOS, F. S. A.; NETTO, C. T. Avaliação de herbicidas no controle de plantas daninhas na cultura da soja. Planta Daninha, Brasília, v. 10, n. 1 e 2, p. $45-49,1992$.

BLANCO, H.G. et al. Observações sobre o período em que as plantas daninhas competem com a soja [Glycine max (L.) Merrill]. O Biológico, Campinas, v.39, n.2, p. 3135, 1973.

BLANCO, H.G.; OLIVEIRA, D.A.; ARAÚJO, J.B.M. Período crítico de competição de uma comunidade natural de mato em soja [Glycine max (L.) Merrill]. In: SEMINÁRIO NACIONAL DE PESQUISA DE SOJA, 1, 1978, Londrina. Anais Londrina: EMBRAPA-CNPSO, 1978. p.151-157.

GELMINI, G.A.; DIEHL, S.R.L. Controle de plantas daninhas na cultura da soja. Campinas, CATI, 1983. 23 p. (CATI. Boletim Técnico, 170).

KISSMANN, K.G. Invasoras não gramíneas em lavouras de soja no Brasil Meridional e possibilidade de controle com bentazon. São Paulo, Basf Brasileira S.A., 1976. 10p. (mimeografado).

RODRIGUES, B.N.; ALMEIDA, F.S. Guia de herbicidas. 3 ed., Londrina: Edição dos Autores, 1995. 675 p. 
